\title{
O Ensino Mediado por Tecnologias na Percepção de Futuras Pedagogas
}

\author{
Technology-Mediated Teaching in Perception of Future Pedagogues
}

\author{
Sidney Lopes Sanchez Junior*aa Patrícia Ferreira Concato de Souza ${ }^{\mathrm{b}}$; Márcia Inês Schabarum Mikuska ${ }^{\mathrm{c}}$

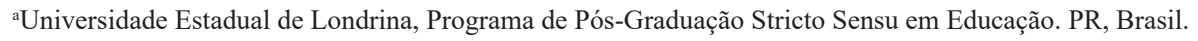

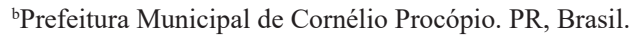 \\ 'Unopar, Programa de Pós-Graduação Stricto Sensu em Metodologia para o Ensino de Linguagens e suas Tecnologias. PR, Brasil. \\ *E-mail: sid.educacaocp@gmail.com
}

\begin{abstract}
Resumo
As Tecnologias Digitais da Informação e Comunicação (TDIC) estão presentes na sociedade e fazem parte da vida cotidiana dos indivíduos, sobretudo nas salas de aula. A partir deste cenário, é fundamental uma ressignificação no processo de ensino e de aprendizagem. O uso das TDIC como estratégia de ensino possibilita ao professor elaborar diversas atividades pedagógicas, principalmente, no âmbito da Ensino Superior. Assim, o objetivo deste artigo é analisar a percepção de futuras pedagogas sobre os conhecimentos que possuem acerca das TDIC, bem como analisar os pontos positivos e negativos da utilização das TDIC nas práticas de ensino. Os sujeitos da pesquisa são acadêmicos do curso de Licenciatura em Pedagogia de uma faculdade privada do Estado do Paraná. Nesse contexto, a coleta de dados foi realizada por meio de um questionário e os dados foram interpretados à Luz da Análise Textual Discursiva. As análises revelam que as participantes possuem um conhecimento sobre o que são TDIC e como pontos positivos evidenciam que as TDIC podem ser utilizadas como estratégia de ensino dinâmica, interessante nas práticas de ensino. Os pontos negativos destacam a falta de capacitação de professores para o trabalho com as TDIC, bem como a utilização sem objetivos específicos de aprendizagem.
\end{abstract}

Palavras-chave: Ensino. Tecnologia Digital da Informação e Comunicação. Educação Superior.

\begin{abstract}
Digital Information and Communication Technologies (TDIC) are present in society and are part of the individuals'daily life, especially in classrooms. Based on this scenario, a new meaning in the teaching and learning process is fundamental. The use of TDIC as a teaching strategy enables the teacher to develop several pedagogical activities, mainly in the University Education context. Thus, the objective of this article is to analyze the perception of future pedagogues about the knowledge they have about TDIC as well as to analyze the positive and negative points regarding the use of TDIC in teaching practices. The research subjects are students from the Pedagogy Degree course at a private college in the state of Paraná. In this context, data collection was carried out through a questionnaire and the data were interpreted in the light of Discursive Textual Analysis. The analyzes reveal that the participants have a knowledge of what TDIC is and how positive points show that TDIC can be used as a dynamic teaching strategy, interesting in teaching practices. The negative points highlight the lack of teacher training to work with TDIC, as well as the use without specific learning objectives.
\end{abstract}

Keywords: Teaching. Digital Information and Communication Technology. College education.

\section{Introdução}

O uso das tecnologias digitais tem aumentado, consideravelmente, nos últimos anos e vem transformando a maneira com que as pessoas se relacionam e acessam as informações (BORBA; SCUGUGLIA; GADANIDS, 2014). As tecnologias estão internalizadas no comportamento dos grupos sociais e é comum ouvir que fazem parte de uma sociedade tecnológica; que o cotidiano é permeado de tecnologias, que refletem diretamente na maneira com que os estudantes estabelecem relações com as informações no contexto escolar (KENSKI, 2012).

O uso das Tecnologias Digitais da Informação e Comunicação (TDIC) ${ }^{1}$ é uma vertente que tem delineado novos rumos para a prática educacional, uma vez que podem ser utilizadas em prol da facilidade em acessar os conhecimentos, bem como estratégias para diversificar o ensino e aprendizagem (CLEOPHAS, et al., 2014). Para Moran (2006), a tecnologia está à serviço do homem, possibilitando o desenvolvimento profissional, sobretudo do professor.

$\mathrm{Na}$ escola, a utilização das Tecnologias da Informação e Comunicação se torna aliada do professor ao possibilitar

1 Opta-se pela utilização de Tecnologias Digitais, por dar a característica de maior abrangência na temática, no entanto, não se desconsideram os autores que utilizam as terminologias: Tecnologias de Informação e Comunicação (TICs); Tecnologias Digitais de Informação e Comunicação (TDIC); Tecnologias Educativas, ou Novas Tecnologias de Informação e Comunicação (NTIC). Desse modo, neste artigo se utilizará a terminologia Tecnologias Digitais, apesar de apresentar diversas citações utilizando TIC e/ou TDCI, uma vez que ambas se complementam. Quando se fala em tecnologias digitais, é importante destacar que se refere ao conjunto de tecnologias que permitem a aquisição, produção e transmissão de informações que podem ser dinamizadas por meio de imagens, de vídeos, de áudio, de textos, de jogos eletrônicos e outros. 
formas diversificadas na elaboração de atividades integradas ao currículoescolar(SOUZA,BLANCO, COELHONETO, 2019).

A este respeito, a Base Nacional Comum Curricular (BNCC) (BRASIL, 2017) ressalta que é fundamental que a escola incorpore as novas linguagens e as formas que podem ser utilizadas, em sala de aula, visto que o uso consciente da tecnologia contribui para a participação na cultura digital.

Dessa forma, a escola pode se beneficiar das contribuições das TDIC ao incorporá-las às práticas educativas, e o professor utilizá-las para atender as demandas da sala de aula. Para Pereira e Andrade (2016), a implementação das TDIC nas práticas pedagógicas dos professores exige capacitação para que façam o uso adequado, enquanto estratégia de ensino, podendo ocorrer tanto na formação inicial como na continuada.

Posto isto, a proposta deste estudo consiste em analisar a percepção de futuras pedagogas sobre os conhecimentos que possuem acerca das TDIC, bem como analisar os pontos positivos e negativos da utilização das TDIC nas práticas de ensino.

As TDIC estão presentes nos documentos oficiais, que orientam as práticas pedagógicas na Educação Básica, Pereira e Andrade (2016) ressaltam que a escola, juntamente com o professor, precisa inserir as TDIC nas ações pedagógicas.

Ao estabelecer dez competências gerais, que devem ser desenvolvidas na Educação Básica, o documento basilar da educação (BNCC) destaca o uso das TDIC de forma crítica, significativa, reflexiva e ética, para que os estudantes produzam e disseminem conhecimentos em contextos escolares ou não. $\mathrm{O}$ documento ainda realça que ao fazer o uso das TDIC, o indivíduo é preparado para o mundo do trabalho, visto a necessidade de desenvolverem competências de forma crítica, ativa, criativa em ambientes que fazem o uso intensivo das tecnologias digitais da informação e comunicação (BRASIL, 2017).

Mesmo que a inserção do computador na prática pedagógica seja recente, as pesquisas revelam que este recurso facilita as relações de ensino e aprendizagem, especialmente, porque por meio do computador o professor pode pesquisar, elaborar atividades, fazer o uso de jogos eletrônicos, acessar ambientes virtuais de aprendizagem, bem como fazer o uso de softwares educativos (TEIXEIRA; COELHO NETO, 2016).

Para Teixeira e Coelho (2016), a inserção do computador no processo de ensino e de aprendizagem tem se mostrado como um facilitador no desenvolvimento da aprendizagem dos alunos. Ademais, esses recursos possibilitam diversificar as práticas pedagógicas, proporcionando uma aprendizagem lúdica, interativa e divertida.

Nessa perspectiva, o uso dos softwares também contribui para uma aprendizagem lúdica, e são definidos como programas desenvolvidos para um determinado sistema computacional, que viabilizam o acesso às informações, e podem ser usados para desenvolvimento de conteúdo das mais diversas áreas do conhecimento (SCHNEIDER; FRANCO; SLOMP, 2017).

Associados à tecnologia digital, os jogos eletrônicos são uma tendência relacionada às TDIC, que contribuem para uma aprendizagem diferenciada e divertida, o qual pode ser inserido em diferentes disciplinas (SILVA et al., 2020).

Destarte, os avanços tecnológicos possibilitaram a elaboração de novas estratégias de ensino, entretanto, o professor precisa buscar meios para lidar com esta nova realidade em sala de aula. Nesse sentido, as crianças e os jovens já dominam o uso do celular, compreendem os programas instalados nos computadores e notebooks, além dos aplicativos disponíveis nos tablets (SILVA; PRATES; RIBEIRO, 2016).

Frente a isso, implementar as TDIC, em suas práticas pedagógicas, requer formação do professor, de modo que o capacite a elaborar estratégias que envolvam o uso de softwares, jogos eletrônicos, imagens, vídeos e outros recursos midiáticos, assim como orienta a BNCC.

O professor, que não domina os recursos midiáticos, mesmo que de forma incipiente, dificulta a implementação de novas práticas de ensino, uma vez que estão imersos em um contexto cultural, que utiliza das tecnologias para produzir conhecimento. Para Arruda (2020), há falhas no processo de formação inicial e continuada do professor para utilização das TDIC, o que resulta em má utilização dos recursos que existem na escola, até mesmo a resistência em aprender utilizá-las corretamente.

Posto isto, o presente estudo tem como objetivo analisar a percepção de futuras pedagogas sobre os conhecimentos que possuem acerca das TDIC, bem como analisar os pontos positivos e negativos da utilização das TDIC nas práticas de ensino.

\section{Material e Métodos}

Este trabalho assume um caráter qualitativo, primeiramente, apresentando uma revisão bibliográfica de literatura sobre o uso das Tecnologias na Educação, sobretudo na formação de futuras pedagogas, tendo como base os autores como (ARRUDA, 2020, BORBA, 2014, BORGES; ALENCAR, 2014) e outros.

Em um segundo momento foi elaborado um questionário online para uma coleta de dados sobre o conhecimento do conceito de TDIC, bem como compreender o que as participantes da pesquisa destacam como pontos positivos e negativos em relação ao uso das TDIC na prática de ensino. Por meio de um convite, as estudantes matriculadas no primeiro e segundo ano de um curso de licenciatura em Pedagogia, em Instituição de Ensino Superior privada, localizada no Norte do Estado do Paraná aceitaram a participação na pesquisa. O período de resposta do questionário ocorreu de 18/02/2020 a 22/02/2020.

As participantes da pesquisa autorizaram a publicação de suas respostas ao assinarem um termo de consentimento livre e esclarecido. Com intuito de preservar a identidade das participantes foram codificadas cada uma delas em E1, E2, E3 e, assim, sucessivamente. Dessa maneira, 11 estudantes responderam ao questionário, com questões que buscavam identificar a idade, ano do curso, a compreensão sobre as TDIC, bem como os pontos positivos e negativos na utilização 
das TDIC na prática de ensino.

As respostas coletadas foram interpretadas à luz da Análise Textual Discursiva (ATD) de Moraes e Galiazzi (2016). Segundo Moraes, a ATD tem como finalidade "construir novas compreensões sobre fenômenos e discursos" (MORAES, 2003, p.52). Para Moraes e Galiazzi (2016, p.118):

A análise textual discursiva tem no exercício da escrita seu fundamento enquanto ferramenta mediadora na produção de significados, e por isso, em processos recursivos, a análise se desloca do empírico para a abstração teórica, que só pode ser alcançada se o pesquisador fizer um movimento intenso de interpretação e produção de argumentos.

A análise textual discursiva é organizada em quatro passos: "1 - Desmontagem dos Textos; 2 - Estabelecimento de Relação; 3 - Captação de novo emergente; 4 - Um processo auto-organizado" (MORAES; GALIAZZI, 2016).

De acordo com os autores supracitados, a Desmontagem dos Textos, primeiro foco, está associada ao processo de unitarização, ou seja, explorar o texto detalhadamente com objetivo de identificar as unidades que compõe a pesquisa. O Estabelecimento de Relações, segunda etapa, se refere à construção de categorias que devem estar ligadas às unidades. A Captação do Novo Emergente, terceira etapa, consiste em uma análise mais profunda, de modo que o metatexto seja resultado desse processo, possibilitando a descrição e a interpretação dos fenômenos investigados. E por último, o Processo AutoOrganizado, do qual emergem as compreensões dos fenômenos estudados (MORAES; GALIAZZI, 2016). De acordo com Moraes (2003), as categorias definidas, com base no referencial teórico, são denominadas a priori, já as emergentes são resultantes das informações que compõe o corpus.

Assim, as respostas coletadas foram organizadas e agrupadas em uma única categoria denominada "Tecnologias da Informação e Comunicação (TDIC)", que pretende identificar os conhecimentos, ou seja, a compreensão das participantes da pesquisa acerca do conceito das TDIC (unidade U1), sobre os pontos positivos (unidade U2) e os pontos negativos (unidade U3) do uso das TDIC na prática de ensino.
Dessa forma, a categoria e as unidades elencadas para análise neste trabalho são apresentadas pela Figura 1, as quais foram elencadas a priori.

Figura 1 - Categoria de Análise

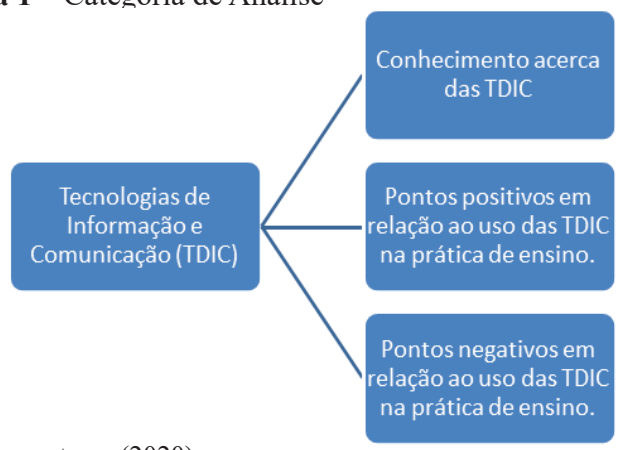

Fonte: os autores (2020)

Importante destacar ao leitor que os fragmentos textuais representativos são apresentados em quadros, buscando a exaustão do corpus analisado, dessa maneira, serão descritos como apresentados pelas participantes, sem correção ortográfica e gramatical. Dessa forma, a próxima seção apresentará os resultados e discussões da pesquisa.

\section{Resultados e Discussão}

Os resultados apresentados visam analisar a percepção de futuras pedagogas sobre o conhecimento e a utilização das TDIC como mediadoras no processo de ensino e de aprendizagem. Verificar os aspectos positivos e os negativos, em relação ao uso das TDIC, como uma estratégia de ensino, também são objetivos elencados neste artigo. As participantes da pesquisa são onze estudantes matriculadas em um curso de Pedagogia, em uma Instituição de Ensino Superior privada do Norte do Estado do Paraná, todas do sexo feminino, com idades entre 19 a 38 anos, cursando o primeiro ou segundo ano do curso.

O Quadro 1 se refere aos excertos da primeira unidade, definida a priori, Conhecimentos acerca das Tecnologias de Informação e Comunicação (TDIC), a qual visou identificar os conhecimentos das estudantes sobre a temática.

Quadro 1 - Categoria: Tecnologias de Informação e Comunicação (TDIC) - Excertos que exemplificam a unidade U1: Conhecimentos acerca das TDIC.

\begin{tabular}{|c|c|}
\hline $\begin{array}{c}\text { Unidade } 1 \\
\text { U1 }\end{array}$ & Excertos \\
\hline $\begin{array}{l}\text { Conhecimentos } \\
\text { acerca das TDIC }\end{array}$ & $\begin{array}{l}\text { Acredito que sejam as tecnologias juntas com um propósito, usadas como um meio alternativo para obter conhecimento (E1). } \\
\text { No meu ver é a internet, celular, tv todos os meios de comunicações (E2). } \\
\text { Não sei muito bem, mas penso que seja algo que envolva todos os tipos de meio de comunicação e tecnologias da atualidade (E3). } \\
\text { Sim. As tecnologias da informação e comunicação ferramentas utilizadas para que aconteça a transmissão de informações (E4). } \\
\text { Não. Nunca me informei sobre. (E5) } \\
\text { Não tenho certeza, imagino que seja algo relacionado ao relacionamento na comunidade em si, é uma tecnologia envolvida nisso, } \\
\text { dentro de pedagogia imagino que seja algo que nos ajude a ter as informações de forma mais diferenciada e que nos ajuda a melhorar } \\
\text { nossa comunicação (E6). } \\
\text { Acredito ser todo e qualquer meio possível da utilização de quaisquer recursos tecnológicos para tornar mais fácil o processo de } \\
\text { conhecimento por meio das comunicações e informações virtuais (E7). } \\
\text { Internet, celular (E8). } \\
\text { Em minha opinião são os recursos tecnológicos utilizados, em sala de aula, como rádios, retroprojetores, tvs, internet, etc Também } \\
\text { jornais, revistas, textos científicos que trarão para dentro da escola o que ocorre na sociedade (E9). } \\
\text { Sim, e está aumentando cada vez mais.(E10) } \\
\text { Sim, são muito importantes, pois atualmente é notável como as tecnologias engessaram no cotidiano das pessoas, e as TDIC são um } \\
\text { reflexo disso.(E11) }\end{array}$ \\
\hline
\end{tabular}


Entre as participantes, oito estudantes apresentaram um conhecimento associado às tecnologias digitais de informação e comunicação. As estudantes (E2, E8, E9) relacionaram as TDIC com: a internet, o celular, a tv, e o rádio.

Nesse contexto, as respostas das participantes se aproximam do conceito de TDIC apresentados pelos autores Souza, Coelho Neto e Blanco (2019) ao destacarem o computador, a internet e os dispositivos móveis (celular ou tablet) como tecnologias digitais de fácil acesso nas instituições escolares. Masseto e Moran (2012, p.53) explicam que a: “[...] internet é uma mídia que facilita a motivação dos alunos, pela novidade e pelas possibilidades inesgotáveis de pesquisa que oferece".

Ademais, vale destacar que a internet auxilia o processo de ensino e aprendizagem, de modo que o docente pode utilizar plataformas digitais para a realização das atividades pedagógicas, bem como a participação em pesquisas: “[...] em tempo real, de um projeto entre vários grupos, de uma investigação sobre um problema da atualidade" (MASETTO; MORAN, 2012, p. 49).

Para Kenski (2012), a televisão e o computador proporcionam ao professor possibilidades de novas estratégias para a mediação dos saberes, pois as imagens, os sons e os movimentos facilitam a compreensão dos conteúdos trabalhados em sala de aula; como destacou a estudante 7 (E7) ao declarar que as TDIC são "todo e qualquer meio possível da utilização de quaisquer recursos tecnológicos para tornar mais fácil o processo de conhecimento por meio das comunicações e informações virtuais".

Para a estudante (E1), as TDIC podem ser definidas como: "tecnologias juntas com um propósito, usadas como um meio alternativo para obter conhecimento”. De Bona e Lutz (2018) destacam que o uso dos recursos tecnológicos são atrativos para os estudantes, visto que já fazem parte da rotina de todos, possibilitando interação, compartilhamento e a interatividade durante o processo de ensino e de aprendizagem dos conteúdos curriculares.

A estudante 6 (E 6) descreve as tecnologias digitais de informação e comunicação com insegurança:

[...] não tenho certeza, imagino que seja algo relacionado ao relacionamento na comunidade em si, é uma tecnologia envolvida nisso, dentro de pedagogia imagino que seja algo que nos ajude a ter as informações de forma mais diferenciada e que nos ajuda a melhorar nossa comunicação.

Para a estudante 6 (E 6), as tecnologias podem facilitar a comunicação, em sala de aula, o que não está errado, pois a tecnologia pode contribuir para a aprendizagem dos estudantes, contudo, a ação do professor é essencial neste processo, para mediar e organizar as práticas educativas com auxílio das TDIC. Desse modo, a autora Kenski (2016, p.45) ressalta que "quando bem utilizadas, provocam a alteração dos comportamentos de professores e alunos, levando-os ao melhor conhecimento e maior aprofundamento do conteúdo estudado".

Percebe-se que os estudantes, participantes da pesquisa, possuem algum conhecimento sobre as TDIC, sobretudo, porque fazem parte de um mundo permeado pelas tecnologias. Contudo, observa-se insegurança e um conhecimento ainda incipiente acerca desta temática, o que indica a necessidade de investimento na formação sobre a utilização das TDIC com objetivos pedagógicos.

O Quadro 2 a seguir caracteriza a unidade: Pontos Positivos em relação ao uso das TDIC na prática de Ensino, que tem como objetivo identificar a percepção das estudantes em relação às contribuições positivas sobre o uso das TDIC na prática de ensino.

Quadro 2-Categoria: Tecnologias de Informação e Comunicação (TDIC) - Excertos que exemplificam a unidade: Pontos positivos em relação ao uso das TDIC na prática de ensino

\begin{tabular}{|c|c|}
\hline $\begin{array}{r}\text { Unida } \\
\text { U }\end{array}$ & Excertos \\
\hline $\begin{array}{c}\text { Pontos } \\
\text { positivos } \\
\text { em relação } \\
\text { ao uso das } \\
\text { TDIC na } \\
\text { prática de } \\
\text { ensino. }\end{array}$ & $\begin{array}{l}\text { [...]hoje um professor sem conhecimento geral não } \\
\text { consegue realizar um bom trabalho. As crianças } \\
\text { hoje já nascem inseridas dentro das tecnologias, e } \\
\text { com isso, para um bom funcionamento das aulas, } \\
\text { os professores devem fazer uso das tecnologias } \\
\text { (E1). } \\
\text { [...] fácil acesso de todos, muito mais rápido. (E2) } \\
\text { [...] o uso dos TDIC possui grandes impactos } \\
\text { positivos na aprendizagem dos alunos trazendo } \\
\text { melhoras positivas na educação Básica Brasileira } \\
\text { (E3). } \\
\text { Quando o professor se alia de forma correta, } \\
\text { essas tecnologias se tornam ferramentas de } \\
\text { produtividade e criticidade (E4). } \\
{[\ldots . .] \text { eu acho que deixa a aula mais dinâmica e }} \\
\text { interessante (E6) } \\
{[\ldots . .] \text { é possível (E7). }} \\
\text { [...] por meio das TDIC acabamos tendo uma } \\
\text { inovação na prática, já que a tecnologia facilita } \\
\text { a comunicação, bem como a interação e a } \\
\text { autonomia, onde através do uso de computadores, } \\
\text { tablet é possível que a criança se sinta mais } \\
\text { confiante e mais capaz em suas funções superiores } \\
\text { (E8). } \\
\text { [...] moderniza o ensino, e sendo algo prático } \\
\text { (E9). } \\
\text { Pela praticidade e a junção de alguns fatores } \\
\text { para o entendimento sobre certo conteúdo. Por } \\
\text { exemplo: através de um vídeo a criança tem o } \\
\text { estímulo visual e auditivo que levará ao cognitivo } \\
\text { (E10). } \\
\text { [...] obviamente não deve ser um recurso } \\
\text { exclusivo, mas sim integrado com outros. } \\
\text { É positivo, pois a educação se molda com a } \\
\text { sociedade e com a tecnologia se agregando cada } \\
\text { vez mais, é necessário termos as informações e } \\
\text { comunicações cada vez mais dinâmicas (E11). }\end{array}$ \\
\hline
\end{tabular}

Fonte: Dados da pesquisa.

Com base nas respostas, às sete participantes apontam TDIC como uma estratégia dinâmica e motivadora de ensino. Souza, Blanco e Coelho Neto (2019) ressaltam que as TDIC se tornam aliadas do professor, além de ser uma estratégia inovadora, possibilita ao professor a utilização de jogos eletrônicos, vídeos, plataformas educacionais, bem como desenvolver atividades nos softwares educativos.

A partir disso, a colocação da E10 afirma que: 
[...] a praticidade e a junção de alguns fatores para o entendimento sobre certo conteúdo. Por exemplo: através de um vídeo a criança tem o estímulo visual e auditivo que levará ao cognitivo.

Libâneo (2004) reitera que o uso do quadro-negro, cadernos, lápis, livros didáticos continuarão sendo utilizados pelo professor, mas não como única forma de mediação dos saberes escolares, o que evidencia a importância em possuir conhecimentos sobre as TDIC. A estudante 1 (E1) destaca que "um professor sem conhecimento geral não consegue realizar um bom trabalho. As crianças hoje já nascem inseridas dentro das tecnologias, e com isso, para um bom funcionamento das aulas, os professores devem fazer uso das tecnologias". Assim, é imprescindível que o professor conheça diversas estratégias metodológicas para atender as crianças em suas demandas de aprendizagem, especialmente, ao fazer o uso adequado das TDIC.

A estudante 11 (E11) afirma que a tecnologia digital deve ser aliada a outras estratégias de ensino:

[...] obviamente não deve ser um recurso exclusivo, mas sim integrado com outros. É positivo, pois a educação se molda com a sociedade e com a tecnologia se agregando cada vez mais, é necessário termos as informações e as comunicações cada vez mais dinâmicas.

Esse excerto vai ao encontro dos os estudos de Silva, Prates e Ribeiro (2016), pois segundo os autores, implementar as tecnologias digitais nos planos de aula não significa excluir as aulas expositivas, o uso do quadro-negro e o livro de didático, mas sim associá-los às estratégias já utilizadas pelo professor.

De acordo com a estudante 8 (E8):

[...] por meio das TDIC acabamos tendo uma inovação na prática, já que a tecnologia facilita a comunicação, bem como a interação e a autonomia, onde através do uso de computadores é possível que a criança se sinta mais confiante e mais capaz em suas funções superiores.

Para essa estudante, o computador é um instrumento que viabiliza o uso das TDIC no ensino, vindo de encontro ao que Souza, Coelho Neto e Blanco (2019) ressaltam, pois por meio do computador, o professor pode elaborar atividades pedagógicas, bem como utilizar jogos eletrônicos, acessar ambientes virtuais e softwares educativos.

$\mathrm{Na}$ perspectiva de Benitti, Seara e Schlindwein (2015) o computador é considerado uma ferramenta poderosa e que possui diversas funções educacionais, possibilitando ao professor enriquecer sua prática por meio de jogos pedagógicos, vídeos, animações, gráficos, bem como utilizar software para elaborar atividades que permitem uma aprendizagem prazerosa, cativante e motivadora. Assim, Ramos (2009, p. 6) apresenta contribuições que o uso das tecnologias digitais propicia aos alunos, que se pode observar:

a) oferece possibilidade de interação;

b) permite o acesso a informações;

c) desperta mais interesse das crianças pelas aulas;

d) possibilita a troca de informações; e) amplia os espaços da sala de aula;

f) viabiliza a socialização de trabalhos através de outros meios;

g) prepara o aluno para o mercado de trabalho;

h) contribui com a inclusão digital dos alunos;

i) torna a aula mais interativa.

A partir dos apontamentos de Ramos (2009) se entende que as tecnologias digitais contribuem, de modo singular, no processo de ensino e aprendizagem, podendo ser utilizada como uma estratégia de ensino para a mediação dos conhecimentos escolares. A autora ainda ressalta que "as tecnologias são ferramentas que ampliam nossos limites, como o computador que amplia nossa capacidade de armazenamento de informações, e também, contribui com a modificação do nosso modo de raciocinar, atuar e pensar no mundo" (RAMOS, 2009, p.1).

As participantes da pesquisa ressaltaram pontos positivos em relação ao uso das TDIC na prática de ensino, sobretudo para mediação dos conteúdos curriculares de uma forma mais dinâmica, envolvente, cativante e lúdica. Contudo, é importante destacar que é essencial que os professores conheçam e dominem tais ferramentas, a fim de implementálas e ressignificar suas práticas pedagógicas.

A próxima unidade (U3) exposta no quadro 3, intitulada: Pontos Negativos em relação ao uso das TDIC, na prática de ensino, tem como objetivo averiguar os aspectos negativos observados nos relatos das estudantes participantes da pesquisa.

Quadro 3 - Categoria: Tecnologias de Informação e Comunicação (TDIC) - Excertos que exemplificam a unidade U3: Pontos negativos em relação ao uso das TDIC na prática de Ensino

\begin{tabular}{|c|l|}
\hline $\begin{array}{c}\text { Unidade 3 } \\
\text { U3 }\end{array}$ & \multicolumn{1}{|c|}{ Excertos: } \\
\hline $\begin{array}{c}\text { Muitos professores não têm uma boa qualificação } \\
\text { para usar esses meios dentro dos ensinos, então } \\
\text { acabam usando de uma forma não produtiva, } \\
\text { fazendo com que os alunos percam o interesse } \\
\text { e as aulas não tenham o rendimento necessário } \\
\text { (E1). } \\
\text { O professor não saber utilizar de forma correta, } \\
\text { informações falsas (E2) } \\
\text { Se não for usado com sabedoria, pode sim } \\
\text { atrapalhar o desenvolvimento dos alunos e até } \\
\text { em relação } \\
\text { ao uso das } \\
\text { TDIC na na de professores (E3). } \\
\text { prática de } \\
\text { ensino. }\end{array}$ & $\begin{array}{l}\text { falta de professores atualizados que se } \\
\text { envolvem com as novas tecnologias, pode causar } \\
\text { por isso, o docente ter uma instrução de como } \\
\text { trabalhar com esses recursos é fundamental (E4). } \\
\text { [... nem tudo que está na internet é verdade e } \\
\text { ao mesmo tempo que é mais fácil achar uma } \\
\text { informação tem que ser muito bem pesquisado } \\
\text { para se ter certeza de que aquilo é realmente } \\
\text { verdade (E5). } \\
\text { Uso inadequado e sem limites pode prejudicar o } \\
\text { ensino (E6). } \\
\text { Se usado só ele na prática de ensino, não usando } \\
\text { também, a parte manuscrita e manual, acaba se } \\
\text { tornando algo muito fácil (E7). }\end{array}$ \\
\hline
\end{tabular}




\begin{tabular}{|c|l|}
\hline $\begin{array}{c}\text { Unidade 3 } \\
\text { U3 }\end{array}$ & \multicolumn{1}{c|}{ Excertos: } \\
\hline & $\begin{array}{l}\text { Acredito que o ponto principal e negativo visto } \\
\text { hoje no mundo seja a total capacidade de nós } \\
\text { enquanto seres humanos estarmos perdendo } \\
\text { essa essência humana. Ao ponto de tudo estar se } \\
\text { tornando superficial e instantâneo (E8). } \\
{[\ldots] \text { pelo mesmo fato de ser algo prático pode-se }} \\
\text { levar ao acomodo. E na sala de aula é sempre } \\
\text { preciso inovar. As tecnologias são para apoiar o } \\
\text { professor no seu trabalho e não para executar a } \\
\text { aula mecanicamente (E9). } \\
\text { Primeiramente a falta de estrutura das instituições } \\
\text { para abrigar adequadamente as TDIC, também } \\
\text { a resistência de profissionais da educação que } \\
\text { possuem uma certa aversão sobre a tecnologia } \\
\text { (E10). } \\
{[\ldots] \text { nem tudo que se mostra através da tecnologia }} \\
\text { é verídico, temos que ficarmos atentos sobre } \\
\text { notícias falsas, e sabermos usar a internet de uma } \\
\text { forma correta (E11). }\end{array}$ \\
\hline
\end{tabular}

Fonte: Dados da pesquisa.

Com base nos excertos apresentados se tornou evidente a falta de qualificação e capacitação dos professores como ponto negativo no uso das TDIC nas práticas de ensino; como se pode observar nas considerações tecidas pelas estudantes (E1, E2, E4) comprometendo de forma negativa a mediação dos conteúdos escolares.

[...] muitos professores não têm uma boa qualificação para usar esses meios dentro dos ensinos, então acabam usando de uma forma não produtiva, fazendo com que os alunos percam $\mathrm{o}$ interesse e as aulas não tenham o rendimento necessário (E1).

[...] professor não saber utilizar de forma correta (E2).

[...] A falta de professores atualizados que se envolvem com as novas tecnologias, podem causar problemas na aprendizagem de seus alunos, por isso, o docente ter uma instrução de como trabalhar com esses recursos é fundamental (E4).

De fato, para que as TDIC sejam utilizadas de forma correta no âmbito escolar, os professores necessitam de formação que contemplem essa estratégia de ensino. Silva; Prates; Ribeiro (2016) explicam que os profissionais de educação necessitam buscar formas de capacitação e aperfeiçoamento para inserir a tecnologia como novas ferramentas pedagógicas, visto que muitos professores ainda seguem as práticas adotadas pelos seus antigos mestres, o que gera uma dificuldade para adequar às novas estratégias de ensino utilizando as TDIC.

Napercepção deArruda(2020), a formação do professornão o prepara para implementar as tecnologias digitais nas práticas pedagógicas, de modo que esses profissionais demonstram um certo receio em utilizá-las por não apresentarem domínio sobre os recursos midiáticos. A estudante 10 (E10) afirma que: "a resistência de profissionais da educação que possuem uma certa aversão sobre a tecnologia". Nesse sentido, Pereira e Andrade (2016) explicam que essa dificuldade dos professores está associada ao fato de que, em sua formação inicial, eles não tiveram a oportunidade de trabalhar com esses recursos.

[...] não é possível pensar na inserção dessas diferentes ferramentas sem pensar na formação dos professores, pois ela deve aproximar os professores das TDIC, oportunizando discussões de pesquisas e problematizando junto aos seus pares os desafios e as possibilidades da integração delas à sua prática pedagógica (PEREIRA; ANDRADE, 2016, p. 64).

Valente (2008) esclarece que a formação do professor necessita promover condições para que ele domine os recursos midiáticos, de modo que ao inserir o uso do computador, notebook, tablet ou smartphones, seja capaz de superar as dificuldades de manusear e elaborar atividades por meio destes recursos. Silva, Prates e Ribeiro (2016, p.113) ressaltam:

A importância do professor adquirir habilidades e técnicas referentes à inclusão de tecnologias digitais, deve-se ao fato de que esses meios estão mais contextualizados com a realidade em que o aluno de hoje vive e, com certeza, vai ser um fator de motivação a mais para despertar o interesse do mesmo. Entretanto, o maior desafio para o professor é integrar essas novas tecnologias aos conteúdos ministrados em sala de aula, pois não basta apenas ter as ferramentas, se não se sabe utilizá-las. Por isso, é importante que o professor busque conhecer e aprender sobre a ferramenta tecnológica que pretende usar para adequá-la ao seu planejamento.

Assim, fica evidente que para que o uso das TDIC seja efetivo, o professor necessita de formação, seja essa inicial ou continuada, mas que o capacite para implementá-las em suas práticas pedagógicas de forma significativa. Souza (2020) reitera que é preciso promover a inclusão digital dos professores, dos pesquisadores e dos alunos, de modo que favoreça a construção do conhecimento, o que também é função das tecnologias digitais.

Cabe ressaltar que a integração das TDIC deve estar associada às práticas do professor, uma vez que seja planejada com objetivos claros elencados. Assim, ao pensar em formação e capacitação do professor, não se pode "visar apenas a capacitação técnica e sim uma formação que o capacite para usar as tecnologias para a inovação pedagógica" (OLIVEIRA; MOREIRA, 2015, p.2).

De acordo com as acadêmicas 5 e 11 (E5 e E11), os pontos negativos relacionados ao uso das TDIC estão associados a internet.

[...] nem tudo que está na internet é verdade e ao mesmo tempo que é mais fácil achar uma informação tem que ser muito bem pesquisado para se ter certeza de que aquilo é realmente verdade (E5).

Sim, porque nem tudo que se mostra através da tecnologia é verídico, temos que ficarmos atentos sobre notícias falsas, e sabermos usar a internet de uma forma correta (E11).

Valente (2014, p.145) expõe que a internet viabiliza a exploração de diversos assuntos, entretanto, é essencial ter um objetivo ao navegar pela internet, pois "se a informação obtida não é posta em uso, se ela não é trabalhada pelo professor, não há nenhuma maneira de estarmos seguros de que o aluno compreendeu o que está fazendo".

Dentro desse contexto, Lobo e Maia (2015) afirmam que a internet é uma fonte inesgotável de informações e que facilitam o processo de pesquisa em função das inúmeras plataformas de busca. 
Os excertos das estudantes estão em concordância com os autores propostos. Ademais, a internet só irá contribuir com o processo de ensino e de aprendizagem se o seu uso for planejado e com objetivos a serem alçados. Desse modo, os pontos negativos podem ser superados em investimentos tanto na estrutura, em equipamentos tecnológicos e em formação e capacitação de professores, que atuam em todas as etapas e modalidades de ensino.

\section{Conclusão}

A TDIC proporciona aos professores diversas possibilidades para a mediação dos conteúdos escolares. O computador, o notebook, os smartphones, a internet, são tecnologias que enriquecem as práticas pedagógicas do professor e contribuem para uma aprendizagem mais efetiva.

O curso de Pedagogia que as estudantes participantes da pesquisa são matriculadas apresenta a disciplina intitulada: “Tecnologias Aplicadas à Educação", ainda no primeiro ano do curso, com carga horária de 70 horas, o que permitiu que as estudantes identificassem as contribuições das TDIC para o ambiente escolar. Contudo, é importante que outras disciplinas contemplem esta temática, visto que podem auxiliar as estudantes a perceberem a possibilidade de utilizar diferentes recursos, buscando uma aprendizagem em diferentes contextos.

Destarte, ao retomar o objetivo geral do presente estudo, o qual consistiu em analisar a percepção de futuras pedagogas sobre os conhecimentos que possuem acerca das TDIC, bem como analisar os pontos positivos e negativos da utilização das TDIC nas práticas de ensino. Considera-se que as futuras pedagogas apresentam uma percepção coerente com os autores que fundamentam esta pesquisa no sentido de identificar as TDIC. Porém necessitam de formação quanto à utilização das TDIC, enquanto estratégia de ensino.

No que tange aos aspectos positivos se verificou que as estudantes apontaram a tecnologia como uma estratégia de ensino interessante e dinâmica, visto que traz contribuições efetivas não apenas na Educação Básica, mas também à Educação Superior. Ademais, a utilização das TDIC, na Educação Superior, proporciona aos alunos recursos para aprofundar suas pesquisas acadêmicas e pode potencializar a aprendizagem.

Em relação aos aspectos negativos se constatou que a falta de formação dos professores para inserir as TDIC, nas práticas pedagógicas, foi a resposta mais reincidente entre os excertos. Assim, é importante destacar que o uso das TDIC, nas práticas pedagógicas, tenha êxito é imprescindível que o professor tenha formação e domínio dessa estratégia de ensino.

Diante do exposto, considera-se que o uso das TDIC contribui, de forma peculiar, para o processo de ensino e de aprendizagem, principalmente, no contexto atual.

Em função da Pandemia do COVID-19, é essencial que os professores ressignifiquem suas práticas pedagógicas, a fim de mediar os conteúdos historicamente acumulados por meio das TDIC. Assim, evidencia-se que o domínio das TDIC é fundamental na formação dessas futuras pedagogas, de modo que as capacite para o uso efetivo desses recursos, tanto na vida acadêmica quanto profissional.

\section{Referências}

ARRUDA, E.P. Educação, educação a distância e tecnologias digitais: perspectivas para a educação pós-Covid-19. Pensar Educ. Rev., v. 6, n.1, 2020.

BENITTI, F.B.V.; SEARA, E.F.R.; SCHLINDWEIN, L. M. Processo de desenvolvimento de software educacional: proposta e experimentação CINTEDUFRGS. Novas Tecnol. Educ., v.3, n.1, p.1-10, 2015.

BORBA, M. C; SCUCUGLIA, R. R. S.; GADANIDIS, G. Fases das tecnologias digitais em Educação Matemática: sala de aula e internet em movimento. Belo Horizonte: Autêntica, 2014.

BORGES, T.S.; ALENCAR, G. Metodologias ativas na promoção da formação crítica do estudante: o uso das metodologias ativas como recurso didático na formação crítica do estudante do ensino superior. Cairu Rev., v.3, n.4, p.119-114, 2014.

BRASIL. Ministério da Educação. Base Nacional Comum Curricular. Educação é base. Brasília: MEC, 2017.

CLEOPHAS, M.G. et al. Alternate reality game (ARG): uma proposta didática para o ensino de química. Rev. Tecnol. Educ., v. 6, n. 11, p. 1-16, 2014.

DE BONA, A.S.; LUTZ, M.R. A tecnologia digital: um recurso que proporciona uma metodologia diferenciada. Rev. Thema, v.1, n.15, p.143-155, 2018. doi: https://doi.org/10.15536/ thema.15.2018.143-155.742

KENSKI, V.M. Educação e tecnologias: um novo ritmo da informação. Campinas: Papirus, 2012.

KENSKI, V.M. Educação e tecnologias: um novo ritmo da informação. Campinas: Papirus, 2016.

LIBÂNEO, J.C. Organização e gestão da escola: teoria e prática. Goiânia: Alternativa, 2004.

MASETTO, M.T. Mediação pedagógica e o uso da tecnologia. In: MORAN, J.M. Novas tecnologias e mediação pedagógica. Campinas: Papirus, 2012. p.133

LOBO, A.S.M.; MAIA, L.C.G. O uso das TIC's como ferramenta de ensino aprendizagem no Ensino Superior. Cad. Geografia, v.25 n.44, p.16-26 2015. doi: https://doi.org/10.5752/P.23182962.2015v25n44p16

MORAES, R. Uma tempestade de luz: a compreensão possibilitada pela análise textual discursiva. Ciênc. Educ., v.9, n. 2, p.191-211, 2003. doi: https://doi.org/10.1590/S1516-73132003000200004.

MORAES, R.; GALIAZZI, M. C. Análise textual discursiva. Ijuí: UNIJUÍ: 2016.

MORAN, J. M. Ensino e aprendizagem inovadores com tecnologias audivisuais e telemáticas. In: MORAN, J.M.; MASETTO, M.; BEHRENS, M. Novas tecnologias e mediação pedagógica. Campinas: Papirus. 2006. p.11-66.

MORAN, J.M. Mudando a educação com metodologias ativas. In: SOUZA, C.A.; MORALES, O. E. T. (Org.). Convergências midiáticas, educação e cidadania: aproximações jovens. 2012. p.15-33. Disponível em: https://br.pinterest.com/ $\operatorname{pin} / 28640147608433495 /$

OLIVEIRA, V. A.; MOREIRA, H. As tecnologias da informação e da comunicação como mediação pedagógica no curso de pedagogia. Rev. Iberoam. Estud. Educ., p. 371-389, 2015. doi: 
https://doi.org/10.21723/riaee.v10i2.7785.

PEREIRA, P.S.; ANDRADE, S.V.R. Tecnologias digitais e as práticas pedagógicas dos professores de Matemática da Educação Básica. Rev. Com a Palavra o Professor, v.1, n.1, p.57-73, 2016. doi: https://doi.org/10.23864/cpp-v1-n1-66.

RAMOS, D.K. A formação de professores para o uso das tecnologias: um mosaico de concepções e emoções. Renote, v.7, n.1, p.1-11, 2009. doi: https://doi.org/10.22456/16791916.14030a

SCHNEIDER, D.R.; FRANCO, S. R. K.; SLOMP, P. F. Software livre na educação: uma experiência em cursos de formação docente. Texto Livre Ling. Tecnol., v. 9, n. 2, p.199- 218, 2016. doi: http://dx.doi.org/10.17851/1983-3652.9.2.199-218.

SILVA, I.C.S; PRATES, T.S; RIBEIRO, L.F.S. As novas tecnologias e aprendizagem: desafios enfrentados pelo professor na sala de aula. Em Debate, n.15, p.107-123, 2017. doi: http:// dx.doi.org/10.5007/1980-3532.2016n15p107.
SILVA, P.; et al. A intenção de uso de jogos virtuais nas aulas de Educação Física escolares. Renote. v.18 n.1, 2020. Disponível em: https://www.seer.ufrgs.br/renote/article/view/105932/57805. Acesso em: 6 jun. 2020.

SOUZA, P.; BLANCO, M.; COELHO NETO, J. Tecnologias digitais e o desenvolvimento da cognição numérica: possibilidades para o ensino da Matemática. RIS, v.2, n.2, p.132-149, 2019. doi: https://doi.org/10.36661/2595-4520.2019v2i2.10818.

TEIXEIRA, C.F.P.; COELHO NETO, J. O uso das tecnologias digitais para o ensino de matemática financeira: uma revisão sistemática de literatura. Rev. Novas Tecnol. Educ., v. 14, n. 2, p.1-10, 2016. doi: https://doi.org/10.22456/1679-1916.70673.

VALENTE, J.A. A comunicação e a educação baseada no uso das tecnologias digitais de informação e comunicação. Rev. UNIFESO, v.1, n.1, p.141-166, 2014.

VALENTE, J.A. Computadores e conhecimento: repensando a educação. Campinas: Núcleo de Informática Aplicada à Educação, 1999. 